\title{
LA BREVEDAD EN EL TALLER LITERARIO DE SALVADOR ELIZONDO
}

\author{
Norma Angélica Cuevas Velasco \\ Universidad Veracruzana \\ ncuevas@uv.mx
}

RESUMEN: Este ensayo tiene como punto de partida una reflexión sobre el modo de existencia de la brevedad en la escritura de Salvador Elizondo, que no está asociado únicamente al asunto de los subgéneros narrativos. Si bien su prosa tiende al relato, adopta formas, estilos y géneros tan diversos que lo más evidente será la búsqueda incesante del ser de la escritura. El apunte, la entrada de un diario o la frase repetida una y otra vez con igual número de variaciones exponen un conjunto de ideas que, sumadas a alguna de las poéticas que es posible espigar en su obra, revelan su pensamiento literario, el cual tiene como vehículo diferentes formas discursivas, tales como los aforismos, el fragmento o las minificciones. La brevedad es el fundamento que sostiene el taller literario de Salvador Elizondo: en ella se origina la experiencia de la escritura y su reflexión.

PALABRAS CLAVE: taller literario, escritura, brevedad, ideas, pensamiento.

\begin{abstract}
This essay has the following as its starting point: the mode of existence of the brevity in Salvador Elizondo's writing is not only associated to the matter of the narrative subgenre. His prose extends to the narration, adopts shapes, styles, and genres so diverse that the most evident thing is the incessant search of the writing's being. The note, the entry of a diary, or the phrase repeated more than once and with an equal number of variations expose a set of ideas that, added to any of the poetics that we can bleam in his work, they reveal his literary thought, which is as different vehicle discursive forms as aphorisms, fragment or short fiction. Brevity in the foundation supporting the literary workshop of Salvador Elizondo: in the brevity of writing cause the experience of writing and reflection.
\end{abstract}

KEYWORDS: literary workshop, writing, brevity, ideas, thought. 
$\S$ De las dimensiones que debe tener el taller del pintor. - El taller del pintor debe ser siempre de menores proporciones que los espacios que el pintor es capaz de concebir mentalmente. Ésta es la regla que rige a la imaginación del pintor cuando está en su taller. ("Tractatus RethoricoPictoricus", El grafógrafo)

Hubiera querido crear, si hubiera sido pintor, una pintura para ser vista sólo en la penumbra o a la luz de la luna. ("La esfinge perpleja", Cuaderno de escritura)

Apreciado como autor raro por José de la Colina, ${ }^{1}$ no por ser un autor olvidado ni despreciado, sino porque ha generado una "sociedad secreta" de lectores de una estirpe también extraña; esa comunidad prefiere, como lo prefirió el propio Salvador Elizondo, la literatura "forastera", distanciada, quizá sólo en apariencia, tanto de las problemáticas sociales de su tiempo como de la fácil arqueología de la tradición, esa que se viste apenas como disfraz de otro que nunca llegará a ser original. Con todo, Salvador Elizondo no constituye una isla, sino que dialoga vívidamente con autores de su cohorte generacional, en México y en toda Hispanoamérica, y se familiariza con escritores en lengua no española. Podría señalarse su labor como traductor, pero no es este el momento para hacerlo, mejor recordemos a los autores leídos por él y por todos los nacidos en los años treinta que, como él, fueron formados en el extranjero o, al menos, tuvieron acceso a una educación bilingüe o políglota: James Joyce, George Bataille, Maurice Blanchot, Aldous Huxley, Stéphane Mallarmé, Arthur Rimbaud, Paul Válery, Ezra Pound, Charles Baudelaire, Fiódor Dostoyesvki, por mencionar a los más evidentes. Esta rareza apunta, también, a que los lectores de Elizondo no serían sus contemporáneos, más bien estarían en un horizonte cultural cuya brecha comienza a cerrarse, al menos en la academia mexicana y en los espacios editoriales impresos o electrónicos, durante la primera década de este siglo XXI.

Para conmemorar el cincuentenario de su magistral novela Farabeuf o la crónica de un instante (1965), El Colegio Nacional no solo preparó, en 2015, una edición de arte (y artesanal también), sino que acompañó esa primicia editorial con una exposición de carteles alusivos a la misma y la montó, con impresionante iluminación, por toda la avenida Juárez de la Ciudad de México. El mensaje era claro: se trataba más que de una instalación de un montaje que incluía palabras e imágenes en una suerte de ejercicio escritural y pictórico que el propio Salvador Elizondo habría con seguridad imaginado (o soñado) para saludar a sus lectores, tanto a los que conforman la secreta e inconfesable comunidad que lo ha seguido con fidelidad desde sus primeras publicaciones hasta ahora; a ellos, digo, pero sobre todo a los nuevos que él sabía que vendrían con el paso de los años. Los estanquillos de periódicos y revistas, junto con las estaciones del metrobús fueron los espacios urbanos que acogieron ese proyecto. Cada uno de esos lugares se sumó a un todo en ausencia: el taller literario de Salvador Elizondo. La finalidad parecía ser la de conformar una galería que mostrara la

\footnotetext{
${ }^{1}$ Véase José de la Colina: “S. E., o del escritor como el Escritor". En Personerío (del siglo XX mexicano). México: Universidad Veracruzana, 2005: 135-141.
} 
vigencia de una obra que, ante todo, homenajeaba a un autor que se concibió a sí mismo como una figuración escritural, como el grafógrafo que todos reconocemos en él: "Vivimos varias vidas diferentes. Para saberlo me basta con echar una ojeada a esa enorme pila de cuadernos. Su apariencia misma delata ese proceso que invariablemente tiende a organizar la vida, clasificándola", escribió Elizondo en "Los trabajos y los días", una de las secciones de sus Diarios, publicada en julio de 2008 por la revista Letras Libres.

Habría que señalar, además, que en este 2016, año en que se cumple una década del fallecimiento de nuestro autor (ocurrida el 29 de marzo de 2006), el Fondo de Cultura Económica publica sus Diarios, en una edición no menos cuidada que la de Farabeuf, pero sin alcanzar la hermosura de aquel libro-objeto. Antes de esto, en 2009, ya había aparecido en España una antología preparada por Daniel Sada bajo el título La escritura obsesiva, así como un volumen editado por Adolfo Castañón: El mar de iguanas (2010), que contiene los Noctuarios de Salvador Elizondo. Ninguno de estos datos sería digno de mención si no se tratara de un escritor cuya obra se produjo básicamente en las décadas de los sesenta y setenta (aunque Elizondo no dejó de escribir sino apenas dos días antes de su muerte), y que fue calificada de cosmopolita y exótica, sin compromiso con la realidad nacional (¡cuál de todas!), como casi toda la producción de sus contemporáneos identificados bajo el nombre de "Generación de Medio Siglo" (o de "La Casa del Lago"), ${ }^{2}$ según se prefiera aludir a la revista que fundaron y en torno a la cual se reunieron, o al espacio físico donde se realizaban muchas de esas reuniones.

Por la infatigable insistencia de escribir sobre la escritura, por incorporar su nombre como personaje e incluso como autor, por hacer de la página un cuerpo al que puede explorársele de manera sutil o violenta, la obra de Salvador Elizondo pronto fue calificada por la crítica y analizada por la academia como ejemplo claro del discurso especular, metaficcional, solipsista, narcisista, ensimismado, autorreflexivo, y se emparentó con la escritura de grado cero o blanca, muy cercana a la estética del nouveau roman. El paso de los años, sin embargo, ha sedimentado esas apreciaciones, que si bien no son erradas, han reducido a una serie de conceptos y categorías más o menos bien definidas el aliento de una obra cuya magia consiste en ser gerundial, esto es, en estar-siendo, de ahí que su movimiento sea, paradójicamente, su mejor sello; subrayo la paradoja en función de la continua búsqueda de la fijeza de la idea por medio de la escritura.

Al tenor de estas consideraciones sería aceptable la afirmación de que la geografía mental de Elizondo es efecto de la recuperación memorística del estado onírico, ese espacio-tiempo donde se confabulan la imaginación, el deseo y la creación para dar origen a la única realidad posible: la escritura: "Un desarreglo de los sentidos sería cuando tenemos la conciencia de que las cosas se desplazan en el tiempo y transcurren en el espacio" ("La esfinge perpleja". En Cuaderno de escritura, 1994: 448). Adviértase en este

\footnotetext{
${ }^{2}$ Para una revisión sobre los integrantes de la llamada "Generación de Medio Siglo", véase Armando Pereira: Narradores mexicanos en la transición de medio siglo (1947-1968), México: UNAM, 2006; y Juan Antonio Rosado y Adolfo Castañón: "Los años cincuenta: sus obras y ambientes literarios". En Manuel Fernández Perera (coord.): La literatura mexicana del siglo XX, México: FCE/CONACULTA/UV, 2008, 261-310.
} 
par de líneas el saber hacer, la poética, que soporta la idea blanchotiana del espacio literario, noción que Elizondo comprendió bastante bien hasta transfigurarla en su propia estética: la escritura es un fenómeno (en el sentido filosófico): algo "que acontece", algo que puede ser observado y, tal vez, descrito.

En los Cuadernos de Elizondo, tanto como en sus Diarios o en sus Noctuarios, la escritura no tiene, empero, la fijeza de la foto sino apenas el disparo de su toma. Son momentos intensos y por eso su duración se recubre de una prolongación inexistente; su existencia verdadera, es decir, su forma, es fugaz y por eso busca repetirse. He aquí la vocación solipsista y rizomática de su escritura: "El espejo es el símbolo de todo porque el espejo es una afirmación que contiene dos certidumbres: el reflejo y el reflejado" ("La esfinge perpleja", 1994: 460).

Actualmente, las lecturas críticas empiezan a señalar otros derroteros, menos anclados a aquellas discusiones académicas encaminadas aún al encuentro de un modelo o a la develación de un género literario otro. La obra de Salvado Elizondo es amplia, pero es posible afirmar con fundada razón - como lo hace Adolfo Castañón- que destacan, además de Farabeuf, El Hipogeo secreto (novela, 1968), Narda o el verano (cuentos, 1966), El retrato de Zoé (cuentos, 1969), Cuaderno de escritura (ensayos, relatos, aforismos, 1969), El grafógrafo (ensayo-relato, minificciones, 1972), Camera lúcida (relatos, ensayos, 1983) y Elsinore (novela corta, 1988). De este listado mínimo, podría decirse que pertenecen a los géneros de la brevedad los dos libros de cuentos y su novela corta, pero pronto aparecerían argumentos para señalar un sinfín de contrariedades, pues sabemos que cada título abarca, a la vez, una serie de discursos con significaciones autónomas posibles tanto como lecturas integradas a la unicidad que todo libro conlleva en su organización y composición textual. La realidad palmaria es que los escritos de Elizondo rehúyen el encasillamiento genérico; la suya es una escritura sin la menor intención de procurar una única o exclusiva forma genérica. La escritura, como las ideas que aportan a la historia del pensamiento, debe existir sin amarres. En esta sintonía van, me parece, las advertencias de Adolfo Castañón:

Salvador Elizondo es, junto con Rafael F. Muñoz, el cuentista mexicano que ha explorado mayor variedad de formas y técnicas narrativas: el diálogo, la carta comercial, el monólogo vocativo, el recuerdo apócrifo, el prospecto turístico, el diagnóstico, la exposición axiomática, la narración a través de múltiples puntos de vista, el ensayo simulado, la descripción taxonómica, el tratado, el diálogo, para sólo enumerar algunas de las formas menos habituales de redacción practicadas por este escritor que es uno de los pocos mexicanos entendidos en las formas retóricas y de la elocuencia clásicas. (1994: IX)

Los lectores de Salvador Elizondo sabemos que su obra es inclasificable o, por lo menos, lo es de manera categórica. Su obra es el proceso de la escritura misma, y en ésta los géneros literarios son ríos profundos, secretos y sinuosos, cuyas aguas constantemente se desbordan para permitir que sus márgenes den origen a otros cauces, más vigorosos unas veces, menos 
caudalosos otras, pero siempre llevando de aquí para allá el ritmo propio de la poesía. ${ }^{3}$ No es la de Elizondo una obra únicamente ficcional, si bien el artificio al desnudo es parte coyuntural de su poética explícitamente metaficcional, lo autobiográfico (y aun lo autoficcional) corren parejas con la idea gerundial del ser de la escritura. Citemos como referentes literarios de estas formas discursivas El hipogeo secreto, Camera lucida y Elsinore. Mucho se ha señalado, con base en la lectura de su Camera lucida, por ejemplo, que la escritura de Elizondo es un laboratorio de ideas (por experimental y ensayística) y sin duda lo es, pero también es un taller, como el del pintor o el del fotógrafo, dos expresiones artísticas caras no solo a la formación del autor sino manifiestas de manera perturbadora en toda su obra. Así lo expresa Elizondo en su "Tractatus RethoricoPictoricus", contenido en El grafógrafo: "§Formas básicas esenciales de la «representación»: la escritura (exposición de la idea en el tiempo) / la pintura (disposición de la idea en el espacio)" (173). De la suma de ambas visiones el resultado es esta prosa con ritmo poético que ya señalé antes.

Integrado por tres grupos de textos que en total suman quince, Cuaderno de escritura es la obra que mejor cristaliza la idea de taller literario. El primero de ellos se titula "La forma del secreto", el segundo es "La cosa mental" y el tercero, "La esfinge perpleja". En este ensayo, como se habrá notado ya, intentaré mostrar, en la medida de lo posible, que "La esfinge perpleja" opera, en la obra de Elizondo, como sinécdoque de su taller literario porque, conformado de fragmentos y aforismos, es posible espigar en él su labor reflexiva, esto es, su pensamiento literario o, al menos, algunas de sus posibles ideas respecto a la escritura y sus formas, que estarán insertas en su textos propiamente narrativos; es decir, sea que el lector lea, ahora, una entrada de sus Nocturarios o de sus Diarios reconocerá inmediatamente el germen que dio origen a una o a varias páginas de las obras antes leídas; acontecimiento ya experimentado a nivel de las ideas si de los Cuadernos y sus "Teorías" hablamos teniendo en el espejo sus relatos, sus ensayos o sus novelas.

Los diccionarios de símbolos y de mitología varían en las descripciones explicativas respecto a la figura de la Esfinge: algunas veces se registra como un monstruo y otras, las menos, como una musa. Entre una y otra figuración persiste la idea de que se trata de un ser tripartita: alado y felino, a la vez con pecho o rostro de mujer. Su gran secreto es la respuesta al siguiente enigma: ¿Qué es lo que por la mañana camina en cuatro patas, a mediodía con dos y por la tarde con tres pies? La respuesta dada por los egipcios revela que se trata del hombre en sus tres edades: infancia (gatear con manos y pies), juventud (caminar en dos pies) y vejez (caminar con apoyo de un bastón). Cabría decir que Elizondo encontró en la musa del enigma la clave metafórica para plantear en las páginas de sus Cuadernos, de sus Diarios y Noctuarios, el proyecto escritural que jamás abandonó, ni en

\footnotetext{
${ }^{3}$ Como he anotado, la obra de Elizondo está escrita mayoritariamente en prosa, pero su ritmo es poético. Al final de este ensayo ofrecemos al lector la transcripción y un comentario de su minificción "El perfil del estípite" que muestra de manera contundente esto que señalo.
} 
estos textos de formas heterogéneas, múltiples y proteicas, ni en sus volúmenes de cuentos o en su novela corta Elsinore.

No es que la división engrane uno a uno, más bien se asoma la intención que más tarde iremos constatando conforme avanza la búsqueda de la obra. Elizondo traza su proyecto literario desde sus primeras páginas, las mismas que conocimos recientemente con la publicación de sus Noctuarios y sus Diarios; un proyecto donde él mismo en tanto autor se constituye como una figuración hecha a la forma de la escritura del tejido que la adopta. Así pues, Elizondo, en el pie de entrada a su Autobiografía precoz, divide su propia vida en tres etapas: "la primera para hablar de los muertos — a leer —; la segunda, para hablar con los vivos — viajar, amar, conversar, escribir-; la tercera para hablar con uno mismo" (2001: 10). La primera etapa abarca desde su nacimiento hasta el abandono de su primera profesión como pintor. ${ }^{4}$ La segunda, que comienza con su matrimonio, es el momento de la escritura, los viajes, el reconocimiento, y finaliza con una recapitulación de su trabajo: La luz que regresa. La última etapa está marcada por un aparente cambio de estilo en la escritura de Elizondo, y la propuesta de una vuelta a la niñez en Elsinore, su autorretrato, para ponerlo en los términos pictóricos que muy seguramente persiguió llevar al "muro de aire", a la página en blanco. Hay que insistir en una cosa: la idea de vivir como personaje de su propio proyecto literario, para lo cual el autor se coloca como una figura más de esa geografía mental que es su escritura. Sólo existe una forma real, concreta, del pensamiento: la escritura. Así lo expresa el autor de Farabeuf: "La escritura es la única prueba que tengo de que pienso, ergo, de que soy. Si no fuera por la escritura yo podría pensar que el pensamiento mismo que concibe la realidad del mundo como una ilusión y como una mentira es, él mismo, una ilusión, una mentira" ("Tractatus Rethorico-Pictoricus". En El grafógrafo, 1994: 172).

De los datos que el autor nos entrega en su Autobiografía precoz, podemos saber que Salvador Elizondo Alcalde nació en la ciudad de México el 19 de diciembre de 1932 dentro de una familia acaudalada. Pasa parte de su infancia en Alemania, donde su padre trabaja en el servicio consular (estará ahí hasta 1939), lo cual tendrá una repercusión más tarde al citar los cuentos relacionados, aparentemente, con su niñez, de E. T. A. Hoffmann, en su novela Farabeuf. La infancia tendrá un lugar importante aunque oscuro en su obra, muchas de sus cavilaciones acerca de la vinculación entre ella y la literatura serán prefiguradas en el ensayo Cuaderno de escritura, "Evocación e invocación de la infancia", y cristalizadas en su tercera novela, Elsinore, lo que indica una tendencia al retorno autobiográfico, a la primera de las tres edades descritas por él mismo, la de "hablar de los muertos". Más tarde y antes del comienzo de la Segunda Guerra Mundial, regresa a México. El shock cultural lo hace sentirse incómodo con las instituciones mexicanas: la

\footnotetext{
${ }^{4}$ Para conocer la formación intelectual de Salvador Elizondo recomiendo ampliamente la lectura de algunas entradas de sus Diarios publicadas en la revista Letras Libres (marzo de 2008), sobre la Nota autobiográfica identificada además como 29-VIII-56, en la que el propio autor se describe como pintor, poeta, crítico y director cinematográfico.
} 
escuela y sus métodos de enseñanza carentes de convicción propia, los "Símbolos Patrios", la moral cristiana.

"La adolescencia es la época en que nuestra falta de discernimiento convierte la amistad en el más elevado de los valores. Yo también he tenido esa flaqueza. Los amigos me iniciaron en el alcohol y en el burdel, pero no en detrimento de mi integridad interior [...]" (2000: 29). El mismo Elizondo se autocalifica como un mal estudiante debido a su incapacidad para adaptarse a la educación mexicana. En su adolescencia lee autores como Dostoievski, Tolstoi, Stendhal y goza de las Rimas de Bécquer.

En esta etapa de su vida es cuando conoce a Silvia - cuando "comienza a hablar con los vivos"-, quien será su esposa y quien le inspira la creación de su primer poema. Estudia en un colegio militar de Estados Unidos de Norteamérica. Posteriormente, al terminar la Preparatoria en la Universidad de Ottawa, decide incursionar en la pintura: estudia artes plásticas en la Academia de San Carlos. Dicha actividad lo pone en contacto con las ideas políticas de izquierda. Despierta su interés la propuesta estética del teórico y director cinematográfico Sergei Eisenstein, e intenta transportarla a sus pinturas y hasta lleva a cabo una cinta para el Festival de Avignon que se tituló Apocalypse Mille Neuf Cent, una narración de fin de siglo, de las revistas científicas francesas, tal y como se afirma en Nexos, en la entrevista "El más allá de la escritura", efectuada por Silvia Lemus (1997).

La visión cinematográfica será tomada como base para su narrativa (no en vano aparece una calle, la "rue Visconti", en su novela Farabeuf) a la que en ocasiones han encuadrado como un collage, en el olvido de que más que una aglomeración de técnicas e imágenes se antepone la tendencia a usar el concepto de "edición”, de montaje. Así lo declara el mismo Elizondo:

Hay oposición dialéctica y síntesis de contrarios, opuestos o diversos de la misma manera que la hay en la escritura china que se funda en el mismo principio en que pretendía yo fundar el texto [se refiere a Farabeuf] en términos generales. Se trata de la aplicación del principio de montaje empleado en el cine mudo, con enorme brillantez por Eisenstein en El acorazado Potemkin, y que consiste en obtener una tercera idea de la oposición o choque de dos ideas anteriores. Tal es el sistema de escritura china: sistema esencialmente metafórico y contextual. Este sistema se aviene bien a la producción de «efectos», lo que es, desde los tiempos de Poe el objetivo primordial que persigue todo el arte moderno. Baudelaire, que fue el primer perseguidor de Poe, había identificado el efecto y la sensación. Yo me basé un poco en la idea, formulada por primera vez por Poe, de que la Belleza no es una causa sino un efecto. Yo quería producir un efecto subjetivo de esa naturaleza (Hölz, 1995: 122-123).

No debe dejarse al margen la influencia de Ezra Pound: de sus Cantares, los cuales fundan la corriente "simultaneísta" en poesía, cuya postura tiene como base la ubicuidad del tiempo; de su reconsideración del Lejano Oriente y, obviamente, de la grafología china, en donde la superposición de signos produce signos nuevos; porque en todo poeta se oculta la obsesión de un cineasta, a decir del propio Elizondo. Recordemos que un ideograma y una fotografía serán nucleares para la configuración de Farabeuf. Es pues, una concepción espacial de la literatura la que corre por la escritura de Elizondo. 
¿Cómo hablar, entonces, de la narrativa o, mejor, de la escritura breve de Salvador Elizondo sin traicionar esta visión estética de la escritura, a un tiempo producto del ejercicio profesional y de una profunda concepción vital de la escritura? En principio y siguiendo las opiniones críticas de finales de siglo XX, podría asociarse la brevedad a la presencia del fragmento, porque fragmentarias suelen ser las perspectivas vocales de sus narraciones, o abismadas las historias de las tramas, o multiplicados, como en espejos, sus personajes, o iterativos los temas asociados a la idea de escritura o la encapsulación escritural de las ideas; y sin embargo algo hay en el fondo de la forma que al tiempo que los rebasa incluye estos fenómenos narratológicos y que constituye, muy posiblemente, el elemento básico de su pensamiento literario. Me refiero a las formas de la brevedad y más específicamente al aforismo, al fragmento y a las minificciones. ${ }^{5}$

La escritura de Salvador Elizondo es muestra palmaria de que la hibridación no se sostiene en la simplicidad de un mestizaje de géneros; las minificciones —ancladas peligrosamente a la fugacidad que encierra todo lo breve - conservan, encapsuladas, la minuciosidad del relojero, la perspicacia del filósofo y la experiencia del poeta. El disfraz de esta forma híbrida va revelándole al lector no caminos, sino cruces: entre la acción y la idea, entre la idea y la imagen, entre esta y el sonido una plétora de varia invención se resuelve en un salto hacia el sentido que, a un tiempo, nos embrolla y nos expulsa de los márgenes del río que corre vertiginoso o se congela sin mayor aviso.

Las minificciones son cuerpos híbridos dibujados a lápiz; sus movimientos espaciotemporales son minuciosos, cautelosos, no siempre apuestan por ocultar los trazos previos a las líneas definitivas. Son, también, cuerpos luminosos, infinitos, llenos de contrastes porque viven en una eterna tensión: a las emociones y a las pasiones se suma la concentración fija de una idea, de una forma de pensar o de percibir el mundo, de imaginarlo, de soñarlo.

Así reflexiona el propio Elizondo a este respecto: "No cabe duda de que el aforismo es una de las formas más elevadas de la escritura literaria. La esencia de este género y excelencia suprema residen en el hecho de que leyendo aforismos nos es imposible leer entre líneas. Un aforismo es lo que leyendo otros géneros creemos leer entre líneas" ("La esfinge perpleja", 457). La brevedad de la escritura de Elizondo pone en crisis toda marca de narratividad tanto o más que su filiación genérica, pues la brevedad, pongamos por caso

\footnotetext{
${ }^{5}$ Si de tomar el riesgo de la taxonomía genérica se tratara, podría aceptarse la propuesta de Javier Perucho respecto a las minificciones que identifica dentro de El grafógrafo; a saber: "El grafógrafo", "Aviso", "Sistema de Babel", "El hombre que llora", "Los hijos de Sánchez", "La señora Rodríguez de Cibolain", "Los indios verdes", "El perfil del estípete", "Novela conjetural", "Presente de infinitivo", "El objeto" y "Experimento nocturno". Javier Perucho sintetiza de manera muy clara las principales líneas discursivas de estas ficciones mínimas: "Los dos primeros son decididos homenajes, por una parte, a Octavio Paz, su amigo y figura tutelar; de la otra, a Julio Torri, inventor de prodigios extraordinarios, de quien pergueña una variación de su celebrado microcuento, a la vez reelaboración del mito de Ulises en su encuentro y seducción por las sirenas («Aviso»). Los siguientes tratan de la invención de una lengua babélica, la violencia hacia los otros para perpetuar el orden de los condóminos, la imperecedera vida de los objetos cotidianos, la otredad, los efectos de la luz, la soledad del hombre contemporáneo y la imposibilidad lógica de los milagros" (www.jornada.unam.mx/2006/08/27/sem-perucho.html).
} 
las minificciones, no consiste sólo en una súbita resolución del conflicto de una trama sugerida, o la configuración de un personaje apenas esbozado con posibilidades de infinita expansión en tanto el lector advierta los intertextos y subtextos a que alude. La brevedad es la idea hecha escritura.

En suma, en la obra de Elizondo, los relatos breves transforman el material literario y se erigen como una meditación sobre la literatura, la belleza y la palabra poética en tanto que su narratividad es puesta en crisis; la escritura breve de Elizondo es poseedora de diversas formas de hibridación y de juegos intertextuales, mismos que la ponen en diálogo con otros discursos. La hibridación es consecuencia de una búsqueda incesante del diálogo con las otras culturas (anglosajona, germana, china, gala, hispanoamericana) y con otras expresiones artísticas (cine, pintura, ideogramas), por eso sorprende que se diga que la complejidad de su escritura la vuelve críptica para los lectores; muy al contrario, es esta disposición al diálogo la cualidad artística mejor lograda y gracias a la cual, probablemente, sea posible asegurar hoy que la de Elizondo es una obra atemporal, clásica para decirlo en una palabra. El espacio literario de Salvador Elizondo es espacio poético, de la poiesis. Espacio más que tiempo.

La intensidad de significaciones y de los efectos de sentidos que logra la brevedad (resultado de un arduo trabajo con el lenguaje) encuentra su contraparte en la ausencia de la clave perfecta que, justamente por no estar escrita, se hace presente durante la lectura architextual a la que la economía de medios conduce al lector, quien ha de realizar un esfuerzo mental crítico, pero sobre todo creativo no para asir el sentido sino para habitar el texto.

Si breve se opone a largo o extenso, si breve se define como contrario a amplio, o si breve es ausencia en oposición a presencia, sería suficiente responder con una ecuación numérica, pero estaría faltando el elemento vital; así lo plantea Elizondo en "La esfinge perpeja": "El conocimiento matemático es un conocimiento sin finalidad. Sólo puede tener una finalidad si se le aúna un elemento irracional: la voluntad. (La voluntad de que tenga una finalidad)" (1994: 441). Tal finalidad es la creación por medio de la escritura; de allí que como he insistido aquí, Salvador Elizondo muestre los pliegues y las costuras del proceso creativo. Su búsqueda no es temática sino discursiva, pues es sólo a través de la palabra enunciada que se abre la posibilidad de emprender la búsqueda del ser de la escritura, que es a su vez el continente del verdadero ser del artista; esta figuración de la palabra enunciada no tiene más modo de existencia que aquel que la obra misma va generando; el artista no existe antes ni después de la obra, sino justamente por ella y en ella. No es fácil encontrar en la escritura de Elizondo ideas literarias fijas, puesto que no se dirige a la definición ni a la clasificación, constantemente se descubre en medio de una fuga no tanto temática, pues ya he recordado que su gran tema es la escritura. No es por esto monótono su discurso y no puede serlo porque nuestro autor sabe introducir las variaciones necesarias mediante el recurso de los espejos, las máquinas, los laberintos, los cuadernos, las fotografías, etcétera. Estas variaciones son, se podría decir, el índice de la fuga que implican esas variaciones. La fuga en todo caso es formal: "El arte es la región ignota del 
mundo. El misterio es la regla de oro de la creación, la obra en sí, la realización de un acto secreto. Sustraer a la forma del mundo para descubrirla, para entregarla luego desnuda, envuelta sólo con la belleza de lo nefando, a la mirada es, quizás, el más jubiloso e infame de los pecados imperdonables: el crear" (1994: 176).

No se trata de saber cuánto es breve, tampoco basta con intentar una definición de brevedad, más valdría preguntarse junto con Elizondo "En qué medida el número es sensible?" ("La esfinge perpleja", 440). No es suficiente con señalar la brevedad —que bien se podría-, la cuestión no sería intentar responder cuándo algo es breve o deja de serlo, se trata, me parece, de algo un poco más complejo y más fascinante también: habría que observar (mirar) y (d)escribir, para comprenderlo, el fenómeno de la brevedad en la escritura de Elizondo, esto es, aceptar en principio que es la brevedad de la escritura la única forma posible mediante la cual la memoria o el pensamiento logran romper la barrera invisible que los separa de la hoja en blanco. Aquí se asoma la vocación filosófica de la escritura: hacer pensar, surtir ideas. Vocación filosófica que, a decir de Salvador Elizondo, trasciende toda convención literaria y cuestiona toda premisa.

\section{Excurso}

El libro titulado El grafógrafo está integrado por 20 textos, cuentos, minificciones, ensayos. En el lugar número once encontramos "El perfil del estípite" que, como he dejado asentado, ha sido considerado una minificción o cuento ultra breve. En efecto, el texto contiene todas las marcas de narratividad exigibles a un cuento: hay sucesión de acciones, o sea que el tiempo transcurre dándole identidad narrativa a los personajes que habitan un espacio $\mathrm{y}$ evidencian un modo de relación con el mundo creado por el discurso.

El cuento breve se compone de dos párrafos: el primero de seis líneas y el segundo de tan sólo dos. El primero acentúa, de entrada, la modalidad narrativa de la enunciación, pero cierra con una descripción que antropomorfiza los objetos de igual modo que como un par de líneas antes lo ha hecho con el gato y el gorrión. La trama se diluye, la historia se cuenta, pesa mucho más la imagen que ha quedado, como la fotografía que revela el sentido de una palabra de modo más preciso que un diccionario.

La sombras, los hilos de luz, la alusión al tiempo: el que fluye y el que se congela ameritan un respiro profundo, inmediato. Ni qué decir de la conjunción de la escritura con la pintura. Este cuento revela la idea de escritura como cosa del espacio. Viene entonces, después de un punto y aparte, el segundo párrafo para dar cuenta del momento justo en que la resolución del sentido buscado ha sido captada por la inteligencia de una realidad concreta: esa forma arquitectónica (o botánica) que es el estípite.

He aquí el cuento breve de Salvador Elizondo:

\section{EL PERFIL DEL ESTÍPITE}

En la hora en que el gato se relame los visos con ríspida lengua. Intempestivamente la escritura agitada del gorrión salpica el cuaderno rayado de la jaula y su nota agridulce y repentina turba el minucioso discurso del reloj. Las blancas geometrías 
de la ventana se postulan abiertas contra el gran muro que apenas las resuelve y por el que resbala la cuña líquida del cielo azul.

Es el momento justo, no más; el instante en el que todo el filo del sol se abate allí, sobre el perfil preciso de la palabra estípite. (El grafógrafo, 1994: 167)

\section{Bibliografía}

BLANCHOT, Maurice (1992): El espacio literario. Trad. Vicky Palant y Jorge Junkis. Barcelona, Paidós.

CASTAÑÓN, Adolfo (1994): "Las ficciones de Salvador Elizondo". En Obras I. México, El Colegio Nacional.

COLINA, José de la (2005): Personerío (del siglo XX mexicano). México, Universidad Veracruzana.

CUEVAS VELASCO, Norma Angélica (2014): El sueño que sueña la verdad. La escritura como paisaje en Salvador Elizondo". En Claudia CARRANZA VERA y Juan Pascual GAY (eds.): Paisajes, parajes, lugares y espacios en la literatura mexicana (siglos XIX y XX). México, El Colegio de San Luis, 109-120.

CUEVAS VELASCO, Norma Angélica (2012): "Yo, Salvador Elizondo: entre el cuaderno y el diario". En Antonio CAJERO VÁZQUEZ (ed.): Intimidades: los géneros autobiográficos y la literatura. México, El Colegio de San Luis, 191-205.

CUEVAS VELASCO, Norma Angélica (2011): "Un sueño de escritura. Elsinore, el cuaderno". En Gustavo JIMÉNEZ AGUIRRE (coord.): Una selva tan infinita. La novela corta en México (1872-2011), Tomo II. México, UNAM/F,L,M, 73-86.

CUEVAS VELASCO, Norma Angélica (2006): El espacio poético en la narrativa. De los aportes de Maurice Blanchot a la teoría literaria y de algunas afinidades con la escritura de Salvador Elizondo. México, Universidad Autónoma Metropolitana - Casa Juan Pablos. ELIZONDO, Salvador (2009): Autobiografía precoz. México, Aldvs.

ELIZONDO, Salvador: "Los trabajos y los días", Letras Libres, julio de 2008, http://www.letraslibres.com/mexico-espana/los-trabajos-y-los-dias, 26/09/2016.

ELIZONDO, Salvador (2001): Elsinore: Un cuaderno. México, Fondo de Cultura Económica.

ELIZONDO, Salvador (1994): Cuaderno de escritura. En Obras I. México, El Colegio Nacional, 345-475.

ELIZONDO, Salvador (1994): El grafógrafo. En Obras II. México: El Colegio nacional, 123-209.

HÖLZ, Karl: “Entrevista con Salvador Elizondo", Iberoamericana 58-59 (1995), 122-123. LEMUS, Silvia: "El más allá de la escritura. Una entrevista con Salvador Elizondo", Nexos 238 (1997 octubre), http://www.nexos.com.mx/?p=8572, 26/09/2016.

PEREIRA, Armando (2006): Narradores mexicanos en la transición de medio siglo (19471968). México, UNAM. 
PERUCHO, Javier: "Salvador Elizondo, el sueño de la escritura", La Jornada Semanal 599 (2006), www.jornada.unam.mx/2006/08/27/sem-perucho.html, 27/08/2016.

PRINCE, Gerald: "Observaciones sobre narratividad", trad. Desiderio Navarro, Criterios 29 (1991), 25-34.

ROSADO, Juan Antonio y Adolfo CASTAÑÓN (2008): “Los años cincuenta: sus obras y ambientes literarios". En Manuel FERNÁNDEZ PERERA (coord.): La literatura mexicana del siglo XX. México: FCE/CONACULTA/UV, 261-310.

(C) Norma Angélica Cuevas Velasco

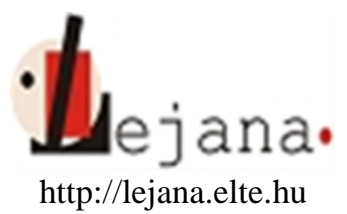

Universidad Eötvös Loránd, Departamento de Español, 1088 Budapest, Múzeum krt. 4/C

Recibido: 30 de mayo de 2016

Aceptado: 04 de julio de 2016 